\title{
Aortic valve replacement in patients with amyloidosis
}

Amit P. Java, MD, ${ }^{a}$ Kevin L. Greason, MD, ${ }^{a}$ Angela Dispenzieri, MD, ${ }^{\mathrm{b}}$ Martha Grogan, MD, ${ }^{c}$ Katherine S. King, MS, ${ }^{d}$ Joseph J. Maleszewski, MD, ${ }^{e}$ Richard C. Daly, MD, ${ }^{a}$ Mackram F. Eleid, MD, Alberto Pochettino, MD, ${ }^{\mathrm{a}}$ and Hartzell V. Schaff, $\mathrm{MD}^{\mathrm{a}}$

\section{ABSTRACT}

Background: Outcome data on aortic valve replacement in patients with amyloidosis are limited. To address this issue, we reviewed our experience of patients with amyloidosis who underwent aortic valve replacement.

Methods: We retrospectively reviewed the records of 16 patients with amyloidosis who underwent aortic valve replacement between May 2000 and February 2017.

Results: The cohort comprised 11 males $(69 \%)$ and 5 females $(31 \%)$. The median patient age was 76 years (interquartile range [IQR], 71-82 years), and Society of Thoracic Surgeons predicted rate of mortality was 5.0\% (IQR, 2.4\%-8.7\%). Amyloidosis type was immunoglobulin light chain in 6 patients $(38 \%)$, agerelated in $6(38 \%)$, and localized in $4(25 \%)$. The operation was surgical aortic valve replacement in 11 patients $(69 \%)$ and balloon-expandable transfemoral transcatheter aortic valve insertion in the other 5. There was no procedurerelated stroke, need for new-onset dialysis or pacemaker, or death within 30 days of surgery. The median length of hospital stay was 1 day (IQR, 12 days) in the transcatheter valve insertion group and 6 days (IQR, 6-8 days) in the surgical group $(P=.002)$. Follow-up was available for all patients at a median of 1.9 years (IQR, 1.2-4.8 years). During the follow-up period, there were 4 deaths, all occurring $>1$ year after surgery.

Conclusions: Aortic valve replacement can be performed with low risk of operative morbidity and mortality in patients with amyloidosis. Transcatheter valve insertion has the advantage of reduced hospital length of stay. The 1-year survival is excellent. (J Thorac Cardiovasc Surg 2018;156:98-103)

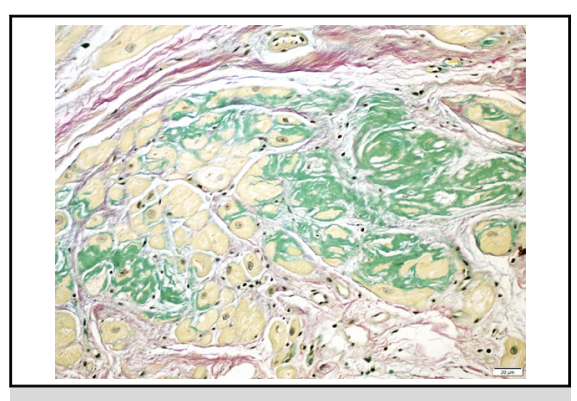

Amyloid protein (green) in atrial myocytes (yellow).

\section{Central Message}

Aortic valve replacement can be done safely and with good intermediate-term mortality outcome in patients with amyloidosis.

\section{Perspective}

In this series of 16 patients with amyloidosis, most of the patients were elderly, with an intermediate risk profile for surgical aortic valve replacement. Outcomes were excellent following both transcatheter and surgical aortic valve replacement. These data support the safety of aortic valve replacement in patients with amyloidosis.

See Editorial Commentary page 104.
Cardiac amyloidosis is an infiltrative restrictive cardiomyopathy that portends a poor prognosis. ${ }^{1-6}$ Although involvement of the myocardium is the most frequent cause of death, some patients also may be affected by valvular or other cardiac pathologies. ${ }^{7-12}$ There are limited data on the risk of aortic valve replacement in patients with amyloidosis. , $^{8,13-17}$ Because the disease

\footnotetext{
From the Departments of ${ }^{\mathrm{a} C a r d i a c}$ Surgery, ${ }^{\mathrm{c}}$ Cardiovascular Diseases, and ${ }^{\mathrm{e}}$ Laboratory Medicine and Pathology, ${ }^{\mathrm{b}}$ Division of Hematology, Department of Internal Medicine, and ${ }^{\mathrm{d}}$ Biomedical Statistics and Informatics, Mayo Clinic, Rochester, Minn.

Received for publication Aug 10, 2017; revisions received Nov 6, 2017; accepted for publication Dec 4, 2017; available ahead of print Feb 2, 2018

Address for reprints: Kevin L. Greason, MD, Department of Cardiovascular Surgery, Mayo Clinic, 200 First St SW, Rochester, MN 55905 (E-mail: greason.kevin@ mayo.edu).

0022-5223/\$36.00

Copyright (c) 2017 by The American Association for Thoracic Surgery

https://doi.org/10.1016/j.jtcvs.2017.12.048
}

often causes severe diastolic dysfunction and affects other organ systems (eg, kidney, liver), we hypothesized that there was potential for increased risk of perioperative morbidity and mortality during aortic valve replacement. ${ }^{3}$ The focus of the present study was on operative and longer-term mortality outcomes in patients with amyloidosis who underwent aortic valve replacement.

\section{METHODS}

The Mayo Clinic's Institutional Review Board approved this study (approval no. 16-010399; February 13, 2017). We performed a retrospective review of the Department of Cardiovascular Surgery's database for

Scanning this QR code will take you to the article title page. 


\section{Abbreviations and Acronyms}
$\mathrm{AL} \quad=$ immunoglobulin light chain type amyloidosis
ATTR $=$ transthyretin/prealbumin type amyloidosis $\mathrm{IQR}=$ interquartile range

all patients who underwent aortic valve replacement between January 2000 and February 2017. This group of 6437 patients was then cross-referenced with the Department of Medicine's amyloidosis database, which at that time contained 2626 patients. There were 16 patients with a diagnosis of amyloidosis any time before or within 3 months of the aortic valve replacement.

Baseline demographic, comorbidity, operative, and follow-up data were recorded as defined in the Society of Thoracic Surgeons Adult Cardiac Database. Vital status was checked through the electronic medical record and an Internet search that included the Social Security Death Index and a general obituary query (accessed October 21, 2017). The primary endpoint of the study was all-cause mortality.

The diagnosis of amyloidosis was based on noncardiac tissue biopsy in 10 patients $(63 \%)$, cardiac tissue biopsy in 5 patients $(32 \%)$, and ${ }^{99 \mathrm{~m}} \mathrm{Tc}-$ PYP single-photon positive emission computed tomography cardiac imaging in 1 patient $(6 \%)$. The cardiac tissue specimens were evaluated by light microscopy using standard clinical protocols. The patients' aortic valves were examined with staining with hematoxylin and eosin $(4 \mu \mathrm{m})$, Verhoeff-van Giesson $(4 \mu \mathrm{m})$, sulfated Alcian blue $(4 \mu \mathrm{m})$, and Congo red $(10 \mu \mathrm{m})$. Only 1 valve showed amyloid deposition, but with only a microfocal deposit of endocardial amyloid identified. All histological analyses were performed by a cardiovascular pathologist (J.J.M.).

Categorical data are reported as count (percentage), and continuous data are reported as median (interquartile range $[\mathrm{IQR}]$ ). A comparative analysis of length of stay between procedure types was done with a nonparametric rank-sum test. Matched pairs analysis was performed by using Wilcoxon-signed rank test comparing preoperative and postoperative echocardiography characteristics. Follow-up was calculated using the reverse Kaplan-Meier method, whereas long-term mortality was calculated using the standard Kaplan-Meier method. Statistical significance was set at $\alpha=0.05$. Data analysis was done with JMP Pro 10.0.0 (SAS Institute, Cary, NC).

\section{RESULTS}

The median patient age was 76 years (IQR, 71-82 years), 5 patients were female (31\%), and Society of Thoracic Surgeons predicted risk of mortality was $5.0 \%$ (IQR, $2.4 \%$ $8.7 \%$ ). Aortic valve stenosis was present in all patients. Additional baseline patient characteristics are reported in Table 1.

The type of amyloidosis was immunoglobulin light chain in 6 patients $(38 \%)$, age-related in 6 patients $(38 \%)$, and localized in 4 patients $(25 \%$; seminal vesicle in 2 , skin in 1 , and pharynx in 1). The diagnosis was confirmed with mass spectrometry in 7 patients and demonstrated transthyretin/prealbumin-type amyloidosis (ATTR; ie, transthyretin; Figure 1) in 5 patients and immunoglobulin light chain-type amyloidosis (AL; ie, immunoglobulin light chain) in 2 patients. The diagnosis of amyloidosis was known before aortic valve replacement in 14 patients $(88 \%)$. In the remaining 2 patients $(12 \%)$, the diagnosis of amyloidosis was made at 47 and 76 days after aortic valve replacement, respectively.

Baseline patient echocardiography demonstrated a median ejection fraction of $60 \%$ (IQR, $59 \%-65 \%$ ). Aortic stenosis was present in all patients. The mean systolic aortic transvalvular gradient was $46 \mathrm{mmHg}$ (IQR, 36-51 mm $\mathrm{Hg}$ ), and the median aortic valve area index was $0.51 \mathrm{~cm} /$ $\mathrm{m}^{2}$ (IQR, $0.39-0.55 \mathrm{~cm} / \mathrm{m}^{2}$ ). The median septal wall thickness was $13 \mathrm{~mm}$ (IQR, 11-14 $\mathrm{mm}$ ), and that of the posterior ventricular wall was $11 \mathrm{~mm}$ (IQR, 10-13 mm).

Transfemoral transcatheter aortic valve insertion was performed in 5 patients $(31 \%)$, all with balloonexpandable valves. Surgical aortic valve replacement was done in the remaining 11 patients $(69 \%)$, using a stented biological valve in 10 patients and a mechanical valve in 1 patient. Concomitant surgical procedures included coronary artery bypass graft operation in 4 patients. The median cardiopulmonary bypass time was 114 minutes (IQR, 69168 minutes), and median aortic cross-clamp time was 99 minutes (IQR, 57-125 minutes).

Procedure-related complications occurred in 3 patients $(19 \%)$. There was a single femoral artery pseudoaneurysm following transcatheter aortic valve insertion in a patient with immunoglobulin light chain amyloidosis (patient 15 in Table 2). In the surgical aortic valve replacement group, there was a case of postoperative tamponade in a patient with age-related amyloidosis (patient 9 in Table 2) and a case of low-output syndrome in a patient with immunoglobulin light chain amyloidosis who presented in cardiogenic shock (patient 6 in Table 2). There were no cases of stroke, new-onset dialysis, or permanent pacemaker implantation.

There was a single case of mild paravalvular regurgitation in the surgical valve replacement group (patient 5 in Table 2), whereas in the transcatheter valve replacement group, paravalvular regurgitation was graded none/trivial in all patients. The median length of hospital stay was 6 days (IQR, 1-8 days) for all patients, 1 day (IQR, 1-2 days) for the transcatheter valve replacement group, and 6 days (IQR, 6-8 days) for the surgical valve replacement group $(P=.002)$. There was also no in-hospital or 30-day mortality.

Follow-up echocardiography data were available in all patients, at a median of 0.6 years (IQR, 0.1-2.4 years). Matched-pairs analysis demonstrated no change from preoperative to last follow-up ejection fraction $(P=.815)$, septal wall thickness $(P=.837)$, or posterior wall thickness $(P=.709)$; however, there was a significant decrease in mean systolic aortic valve gradient from $46 \mathrm{~mm} \mathrm{Hg}$ to $14 \mathrm{~mm} \mathrm{Hg}$ (median difference, $-31(-31--20) \mathrm{mm} \mathrm{Hg}$; $P<.001)$.

Vital status follow-up was complete for all patients at a median of 1.9 years (IQR, 1.2-4.8 years). One patient underwent subsequent tricuspid valve repair 4 months after the initial surgical aortic valve replacement (patient 12 in Table 2). During the follow-up period, there were 4 deaths, 
TABLE 1. Patient baseline characteristics

\begin{tabular}{|c|c|}
\hline Characteristic & Value \\
\hline \multicolumn{2}{|l|}{ Continuous data, median (interquartile range) } \\
\hline Age, y & $76(71-82)$ \\
\hline Body mass index, $\mathrm{kg} / \mathrm{m}^{2}$ & $28(26-31)$ \\
\hline Creatinine, $\mathrm{mg} / \mathrm{dL}$ & $1.2(1.0-1.7)$ \\
\hline Ejection fraction, $\%$ & $60(59-65)$ \\
\hline $\begin{array}{l}\text { Society of Thoracic Surgeons predicted risk of } \\
\text { mortality, } \%\end{array}$ & $5.0(2.4-8.7)$ \\
\hline \multicolumn{2}{|l|}{ Categorical data, n $(\%)$} \\
\hline Female sex & $5(31)$ \\
\hline Caucasian race & $16(100)$ \\
\hline Diabetes & $4(25)$ \\
\hline Dialysis & $1(6)$ \\
\hline Hypertension & $15(94)$ \\
\hline Infectious endocarditis & $0(0)$ \\
\hline \multicolumn{2}{|l|}{ Chronic lung disease } \\
\hline None & $11(69)$ \\
\hline Mild & $3(19)$ \\
\hline Moderate & $1(6)$ \\
\hline Severe & $1(6)$ \\
\hline Immunosuppression & $1(6)$ \\
\hline Peripheral vascular disease & $3(19)$ \\
\hline Cerebrovascular disease & $1(6)$ \\
\hline Previous pacemaker & $2(13)$ \\
\hline Previous coronary artery bypass graft operation & $0(0)$ \\
\hline Previous valve procedure & $1(6)$ \\
\hline Previous percutaneous coronary intervention & $3(19)$ \\
\hline Previous myocardial infarction & $0(0)$ \\
\hline \multicolumn{2}{|l|}{ New York Heart Association class } \\
\hline I & $1(6)$ \\
\hline II & $8(50)$ \\
\hline III & $5(31)$ \\
\hline IV & $2(13)$ \\
\hline Cardiogenic shock & $1(6)$ \\
\hline Resuscitation & $1(6)$ \\
\hline Atrial arrhythmia & $2(13)$ \\
\hline Medical inotropes & $1(6)$ \\
\hline \multicolumn{2}{|l|}{ Number of diseased coronary vessels } \\
\hline None & $7(44)$ \\
\hline 1 & $3(19)$ \\
\hline 2 & $4(25)$ \\
\hline 3 & $2(13)$ \\
\hline Left main coronary artery stenosis $>50 \%$ & $4(25)$ \\
\hline Aortic stenosis & $16(100)$ \\
\hline Mitral stenosis & $4(25)$ \\
\hline \multicolumn{2}{|l|}{ Aortic valve regurgitation } \\
\hline None & $2(13)$ \\
\hline Trivial & $4(25)$ \\
\hline Mild & $6(38)$ \\
\hline Moderate & $2(13)$ \\
\hline Severe & $2(13)$ \\
\hline \multicolumn{2}{|l|}{ Mitral valve regurgitation } \\
\hline None & $1(6)$ \\
\hline Trivial & $6(38)$ \\
\hline Mild & $4(25)$ \\
\hline
\end{tabular}

TABLE 1. Continued

\begin{tabular}{lc}
\hline \multicolumn{1}{c}{ Characteristic } & Value \\
\hline Moderate & $5(31)$ \\
Severe & $0(0)$ \\
Tricuspid valve regurgitation & \\
None & $1(6)$ \\
Trivial & $9(56)$ \\
Mild & $4(25)$ \\
Moderate & $2(13)$ \\
Severe & $0(0)$ \\
Incidence of cardiac operation & \\
First & $15(94)$ \\
Second & $1(6)$ \\
Status elective & $15(94)$ \\
Mechanical assistance & $0(0)$ \\
\hline
\end{tabular}

all of which occurred $>1$ year after surgery. One patient with immunoglobulin light chain amyloidosis died at 3.8 years after surgery (patient 1 in Table 2; cause not specified). One patient with age-related amyloidosis died at 1.7 years after surgery (patient 4 in Table 2; cause not specified), 2 patients with localized amyloidosis died, 1 at 1.5 years after surgery (patient 8 in Table 2; cause not specified) and the other at 7.4 years after surgery (patient 2 in Table 2; cause, giant cell arteritis).

\section{DISCUSSION}

This study reports our experience with 16 patients with amyloidosis who underwent aortic valve replacement. This group of patients was relatively elderly, with a median age of 76 years, and at intermediate risk for surgical aortic valve replacement, with a Society of Thoracic Surgeons predicted risk of mortality of $5 \%$. Aortic valve replacement was surgical in 11 patients and via transfemoral transcatheter in 5. Procedure-related outcomes were outstanding, with no strokes, no need for new-onset dialysis or pacemaker implantation, and no 30-day mortality. Additional longer-term follow-up demonstrated the first postoperative mortality occurring 1.5 years after surgery.

Most of the available literature on amyloidosis and cardiac surgery is focused on the infiltrative cardiomyopathy and the role of heart transplantation in affected patients. ${ }^{18}$ In our institution, between 1992 and 2011, 12\% of heart transplant recipients had amyloidosis (R.C. Daly, personal communication, October 20, 2017). Data are limited on the role of valve surgery in the treatment of patients with amyloidosis, however, with previous reports limited to case reports or small case series. ${ }^{7-9,13-17}$ In a study of 6 patients reported by Treibel and colleagues, ${ }^{8}$ at a median follow-up of 2.3 years after aortic valve replacement, $50 \%$ of patients with amyloidosis had died. The present case series adds additional important data and analysis for patients with amyloidosis who underwent aortic valve replacement. 
TABLE 2. Patient specific operative and outcome data in chronological operative order

\begin{tabular}{llllll}
\hline Patient & Age at operation, $\mathbf{y}$ & \multicolumn{1}{c}{ Amyloid type } & $\begin{array}{l}\text { Aortic valve } \\
\text { replacement }\end{array}$ & $\begin{array}{c}\text { Duration of } \\
\text { follow-up, } \mathbf{y}\end{array}$ & Vital status at last follow-up \\
\hline 1 & 71 & AL & Surgical & 3.8 & Dead \\
\hline 2 & 75 & Localized (skin) & Surgical & 7.3 & Dead \\
\hline 3 & 81 & Localized (seminal vesicle) & Surgical & 8.6 & Alive \\
\hline 4 & 83 & Age-related & Surgical & 1.7 & Dead \\
\hline 5 & 67 & Age-related & Surgical & 4.8 & Alive \\
\hline 6 & 70 & AL & Surgical & 3.9 & Alive \\
\hline 7 & 82 & Age-related & Surgical & 3.1 & Alive \\
\hline 8 & 78 & Localized (seminal vesicle) & Surgical & 1.5 & Dead \\
\hline 9 & 82 & Age-related & Surgical & 1.9 & Alive \\
\hline 10 & 79 & AL & Transcatheter & 1.7 & Alive \\
\hline 11 & 75 & Localized (pharynx) & Surgical & 1.7 & Alive \\
\hline 12 & 70 & Age-related & Surgical & 1.5 & Alive \\
\hline 13 & 95 & Age-related & Transcatheter & 0.8 & Alive \\
\hline 14 & 68 & AL & Transcatheter & 0.8 & Alive \\
\hline 16 & 74 & AL & Transcatheter & 0.8 & Alive
\end{tabular}

$A L$, Immunoglobulin light chain-type amyloidosis.

Our procedural outcomes were excellent, with minimal procedure-related morbidity and no 30-day mortality. Galat and colleagues ${ }^{17}$ also reported no procedure-related deaths in their series of 11 patients with amyloidosis who underwent aortic valve replacement, and Terada and associates ${ }^{15}$ published a case report with a successful outcome. Outcomes following aortic valve insertion or surgical replacement in patients with amyloidosis have not been uniformly good, however. Previous reports have described deaths from left ventricular apical rupture after transapical transcatheter

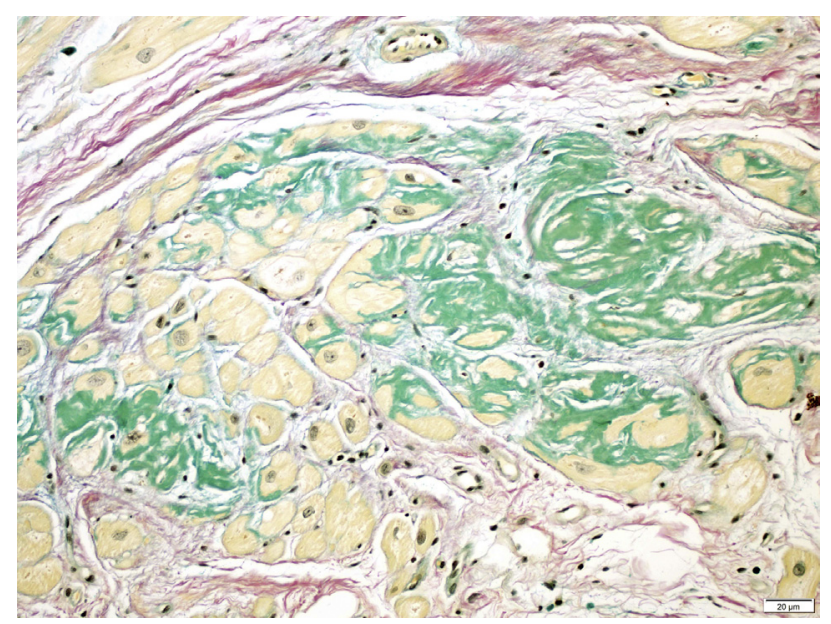

FIGURE 1. Transthyretin/prealbumin (ATTR)-type cardiac amyloidosis. This photomicrograph shows discrete pericellular deposition of amyloid protein (green) in the interstitium between the atrial myocytes (yellow) (sulfated Alcian blue stain; original magnification, $400 \times$ ). aortic valve insertion $(\mathrm{n}=1)$ and from low cardiac output syndrome after surgical valve replacement $(\mathrm{n}=2){ }^{13,14,16}$

Our reported mortality outcome was also encouraging, with no mortality within 1 year of operation. This is in contrast to the relatively high early mortality reported by Galat and colleagues ${ }^{8}$ (post hoc Kaplan-Meier 1-year mortality estimate, $19.1 \% \pm 10.0 \%)$ and Treibel and colleagues $^{17}(50 \%$ mortality at a median follow-up of 2.3 years). In another study of 171 patients with ATTRtype cardiac amyloidosis, Sperry and colleagues ${ }^{7}$ reported a 2-year mortality rate of $37 \%$ in patients with aortic valve stenosis. Our reported outcomes should be viewed in the context of natural history data of patients with symptomatic severe aortic valve stenosis, transcatheter aortic valve insertion, and amyloidosis. $1,4,7,8,19$

Two types of amyloidosis commonly affect the heart: immunoglobulin light chain-associated amyloidosis and age-related transthyretin amyloidosis (most commonly wild-type transthyretin, previously called "senile" cardiac amyloidosis). The presence of immunoglobulin light chain cardiac amyloidosis carries a particularly poor prognosis, with a median survival of 6 months after the onset of overt heart failure in untreated patients. ${ }^{1,6,14,20}$ In contrast, patients with age-related (wild-type transthyretin) amyloidosis have a more indolent clinical course, although the median survival of approximately 3.5 years from diagnosis is significantly worse than predicted. ${ }^{2}$

The possible role of amyloid protein in the development of aortic stenosis is unknown. Although some series have reported high incidences of valvular involvement by 
amyloid in the setting of aortic stenosis, histopathological examination of a subset of our cohort revealed only 1 patient with microfocal deposition (Figure 1). ${ }^{12,21}$ On critical analysis, those previous studies do not definitively prove the presence of amyloid in these specimens. Given the fact that abundant collagen (such as seen in aortic valves) can produce a false-positive Congo red stain, ultrastructural or proteomic data should be used to confirm the presence of amyloid, and neither previous study proffered such data.

Operative decision making is complex in these patients. The decision to operate depends on the type of amyloidosis, severity of cardiac involvement, and overall prognosis, which can be determined using cardiac biomarker staging systems. ${ }^{5}$ The majority of our patients would be classified as intermediate risk for surgical aortic valve replacement. These patients would qualify for US Food and Drug Administration-approved transcatheter aortic valve insertion. ${ }^{22}$ The technique appears to an acceptable option in this group, given the relatively advanced age combined with the lack of procedure-related morbidity, associated short length of hospital stay, and excellent 1-year mortality outcome.

All of our patients who underwent transcatheter valve insertion had a good outcome, but of note, insertion was performed via transfemoral arterial access in all these patients. A good operative outcome was also reported in the 2 patients with transcatheter valve insertion reported by Galat and colleagues, ${ }^{17}$ but the authors did not specify the method of arterial access. In the previously mentioned transapical access case report by Monticelli and colleagues, ${ }^{16}$ the outcome was poor, however. In that case, the patient died from left ventricular apical rupture presumably related to amyloid infiltration of the ventricular apex and weakening of the access puncture repair site. At present, we urge caution with the transapical approach in patients with cardiac amyloidosis.

This study has several limitations, the most important of which is our small cohort of only 16 patients, representing only a minor percentage $(<1 \%)$ of the patients with amyloidosis seen at our institution during the study period. Given the limited number of patients, this study is at risk for type II statistical error in accepting the null hypothesis that valve replacement is safe. In addition, this single-center study is subject to local referral and treatment biases that might not apply to other health care institutions. Finally, there are varying degrees of amyloidosis and cardiac involvement. The diagnosis of amyloidosis is not simple, and thus our rate of presentation is likely an underestimate.

\section{CONCLUSIONS}

There are limited data available on aortic valve replacement in patients with amyloidosis. Our procedural outcomes were excellent following both transcatheter aortic valve insertion and surgical valve replacement. In this series, most of the patients were elderly, with an intermediate operative risk profile for surgical aortic valve replacement. Transfemoral transcatheter aortic valve insertion appears to be an excellent option in these patients, and the operation should not be denied.

\section{Conflict of Interest Statement}

Authors have nothing to disclose with regard to commercial support.

\section{References}

1. Grogan M, Dispenzieri A, Gertz MA. Light-chain cardiac amyloidosis: strategies to promote early diagnosis and cardiac response. Heart. 2017;103:1065-72.

2. Grogan M, Scott CG, Kyle RA, Zeldenrust SR, Gertz MA, Lin G, et al. Natural history of wild-type transthyretin cardiac amyloidosis and risk stratification using a novel staging system. J Am Coll Cardiol. 2016;68:1014-20.

3. Chakraborty R, Muchtar E, Gertz MA. Newer therapies for amyloid cardiomyopathy. Curr Heart Fail Rep. 2016;13:237-46.

4. Sharma N, Howlett J. Current state of cardiac amyloidosis. Curr Opin Cardiol. $2013 ; 28: 242-8$.

5. Dispernzieri A, Gertz MA, Kyle RA, Lacy MQ, Burritt MF, Therneau TM, et al. Prognostication of survival using cardiac troponins and N-terminal pro-brain natriuretic peptide in patients with primary systemic amyloidosis undergoing peripheral blood stem cell transplantation. Blood. 2004;104:1881-7.

6. Kyle RA, Linos A, Beard CM, Linke RP, Gertz MA, O'Fallon WM, et al. Incidence and natural history of primary systemic amyloidosis in Olmstead County, Minnesota, 1950 through 1989. Blood. 1992;79:1817-22.

7. Sperry BW, Jones BM, Vranian MN, Hanna M, Jaber WA. Recognizing transthyretin cardiac amyloidosis in patients with aortic stenosis: impact on prognosis. JACC Cardiovasc Imaging. 2016:9:904-6.

8. Treibel TA, Fontana M, Gilberston JA, Castelletti S, White SK, Scully PR, et al. Occult transthyretin cardiac amyloid in severe calcific aortic stenosis: prevalence and prognosis in patients undergoing surgical aortic valve replacement. Circ Cardiovasc Imaging. 2016;9:e005066.

9. Castano A, Narotsky DL, Hamid N, Khalique OK, Morgenstern R, DeLuca A, et al. Unveiling transthyretin cardiac amyloidosis and its predictors among elderly patients with severe aortic stenosis undergoing transcatheter aortic valve replacement. Eur Heart J. 2017;38:2879-87.

10. Helder MR, Schaff HV, Nishimura RA, Gersh BJ, Dearani JA, Ommen SR, et al. Impact of incidental amyloidosis on the prognosis of patients with hypertrophic cardiomyopathy undergoing septal myectomy for left ventricular outflow tract obstruction. Am J Cardiol. 2014;114:1396-9.

11. Dubrey SW, Cha K, Skinner M, LaValley M, Falk RH. Familial and primary (AL) cardiac amyloidosis: echocardiographically similar diseases with distinctly different clinical outcomes. Heart. 1997;78:74-82.

12. Kristen AV, Schnabel PA, Winter B, Helmke BM, Longerich T, Hardt S, et al. High prevalence of amyloid in 150 surgically removed heart valves: a comparison of histological and clinical data reveals a correlation to atheroinflammatory conditions. Cardiovasc Pathol. 2010;19:228-35.

13. Seki T, Hattori A, Yoshida T. Hemodynamic deterioration after aortic valve replacement in a patient with mixed systemic amyloidosis. Gen Thorac Cardiovasc Surg. 2017;65:470-3.

14. Fitzmaurice GJ, Wishart V, Graham AN. An unexpected mortality following cardiac surgery: a post-mortem diagnosis of cardiac amyloidosis. Gen Thorac Cardiovasc Surg. 2013;61:417-21.

15. Terada Y, Wanibuchi Y. Aortic valve replacement in a patient with cardiac amyloidosis. Ann Thorac Surg. 1996;62:1571-2.

16. Monticelli FC, Kunz SN, Kellar T, Bleiziffer S. Cardiac amyloidosis as a potential risk factor for transapical transcatheter aortic valve implantation. J Card Surg. 2014;29:623-4.

17. Galat A, Guellich A, Bodez D, Slama M, Dijos M, Zeitoun DM, et al. Aortic stenosis and transthyretin cardiac amyloidosis: the chicken or the egg? Eur Heart J. 2016;37:3525-31.

18. Tuzovic M, Yang EH, Baas AS, Depasquale EC, Deng MC, Cruz D, et al. Cardiac amyloidosis: diagnosis and treatment strategies. Curr Oncol Rep. 2017;19:46.

19. Leon MB, Smith CR, Mack MJ, Makkar RR, Svensson LG, Kodali SK, et al Transcatheter or surgical aortic-valve replacement in intermediate-risk patients. N Engl J Med. 2016;374:1609-20. 
20. Buja LM, Khoi NB, Roberts WC. Clinically significant cardiac amyloidosis: clinicopathologic findings in 15 patients. Am J Cardiol. 1970;26: 394-405.

21. Audet A, Côté N, Couture C, Bossé Y, Després JP, Pibarot P, et al. Amyloid substance within stenotic aortic valves promotes mineralization. Histopathology. 2012;61:610-9.

22. Fornell D. FDA expands Sapien TAVR valve indication to intermediate-risk patients. Diagn Interv Cardiol. Available at: https://www.dicardiology.com/article/ fda-expands-sapien-tavr-valve-indication-intermediate-risk-patients. Accessed May 28, 2017.

Key Words: amyloid, amyloidosis, cardiac amyloid, cardiac amyloidosis, aortic valve, aortic valve stenosis, surgical aortic valve replacement, transcatheter aortic valve insertion, transcatheter aortic valve replacement 